DOI https://doi.org/10.30525/978-9934-26-110-7-84

\title{
PROJECT-BASED LEARNING FRAMEWORK FOR ESP IN THE CONTEXT OF ONLINE AND REMOTE EDUCATION
}

\author{
Onyshchuk I. Yu. \\ PhD in Linguistics, \\ Associate Professor at the Department of Foreign Languages \\ for the Humanities \\ I. I. Mechnikov National University
}

Matovych O. O.

PhD in Linguistics,

Lecturer at the Department of Foreign Languages for the Humanities

I. I. Mechnikov National University

Odesa, Ukraine

The world of education has been disrupted by the Covid-19 pandemic. Both teachers and students have encountered certain difficulties by being thrown in the world of online or distance education with little preparation and experience if any. Teaching and learning a foreign language attract special attention with this view. In the past there was much concern about the issue if a foreign language should be taught and learnt using technology, currently language instructors have been forced to harness online and digital tools as technology became the only possible means of communication. Despite being exhausting and challenging, it's been beneficial as well, both teachers and students have learnt a lot from each other, both have gained hands-on experience. In this work we'll look at the students' feedback concerning their first experience of a certain online activity, project work. It will help reflect on the issues that emerged and utilize them in future to make online sessions as interactive and productive as those offline lessons.

The focus group was represented by 48 third-year students of the Department of International Relations. The course studied was an ESP course: English for International Relations. ESP methodology is the way in which language learning and subject learning approaches are frequently integrated [1, p. 192]. The examples of subject learning approaches that have been adopted in ESP situations are case studies and project work. Project work is an essential part of the course syllabus of the above mentioned specialism and comprises $20 \%$ of the learners' final score. According to Thomas [2, p. 1] project-based learning (PBL) is a model that organizes learning around projects which are complex tasks, based on challenging questions or problems, involving students in design, problem-solving, decision making, or 
investigative activities; giving students the opportunity to work relatively autonomously over extended periods of time; and culminating in realistic products or presentations. Students receive the necessary language input and relevant feedback from the language instructor and their peers. With the end of the term questionnaire we explored whether the online learning affected the students' involvement and performance, psychological aspects were also concerned.

$82 \%$ of the learners didn't experience any difficulties while working at the project. They considered it as an opportunity to do their best and to benefit from the remote learning. The first thing the learners mentioned was easy access to the educational process, they could work in teams contributing equally to the success of the group irrespective of many factors: their current location, health issues, job, etc. They demonstrated the remarkable degree of autonomy; the learners took one of the burning issues related to the sphere of International Relations, searched out information to understand the origin of the issue and the possible solution, created the platform with the materials for their presentation available for every learner. In its turn it maximized their exposure to the language and authentic materials guiding learners toward the language they needed for their particular context. The lower-level learners coped with the materials and tasks set pretty well, they were not pressed for time, the main difficulty they might encounter in the classroom. They could work and prepare for every stage at their own pace meeting the deadlines and allocating time in order to perform effectively and not to lag behind the group.

Looking at the social and psychological aspects of online learning, the following issues emerged. Coleman states that project work offers numerous benefits relating to students' increased social, cooperative skills and group cohesiveness [3, p. 36]. Also it reinforces social relationships among the members of the group. We found that $50 \%$ of the learners considered remote learning as a comfortable and more relaxed mode of interaction. Studying from home they were less stressed, more focused as nobody distracted them from educational process. While the other group of students was anxious about studying at home, they felt lonely, sometimes even bored. Interestingly, this fact challenges Maslow's hierarchy of needs, motivational theory in psychology. Maslow initially stated that before a student's cognitive needs could be met, they must first fulfill their basic physiological needs [4, p. 12]. Students need to feel emotionally and physically safe to progress and reach their full potential. Such contradiction could be explained by the fact that learning didn't take place in a traditional learning environment. The learners lacked socializing and face-to-face communication which slightly affected their performance while presenting the results of the project work.

In this work we analyzed students' feedback concerning their first experience of remote learning and online project work in the context of an ESP course: English for International Relations. The majority of students (82\%) 
experienced no difficulties while working on the project. Despite the contradiction in general attitude towards remote learning and unusual learning environment, the students demonstrated more self-discipline and initiative and successfully managed to coordinate project work, divide responsibilities and exploit technology, which resulted in a high-quality project presentation. Overall the learners managed to perform effectively and benefit from the remote learning. The results of this work may be used for further analysis and improvement of online and distance education routine.

\title{
References:
}

1. T. Dudley-Evans and M. J. St John (2012).Developments in English for Specific Purposes. A Multi-disciplinary approach. Cambridge University Press.

2. J. W. Thomas, A Review of Research on Project-Based Learning, 2000. Retrieved September 10, 2009 from www.bobpearlman.org/ BestPractices/PBL_Research.pdf

3. J. A. Coleman, Project-based learning, transferable skills, information technology and video, Language Learning Journal, 5, 35-37, 1992

4. S.A. McLeod (2020, March 20). Maslow's hierarchy of needs. Simply Psychology. https://www.simplypsychology.org/maslow.html

DOI https://doi.org/10.30525/978-9934-26-110-7-85

\section{«PEER FEEDBACK» AS AN ALTERNATIVE ASSESSMENT METHOD IN EFL TEACHING IN SENIOR CLASSES}

\author{
Slyvka M. I. \\ Candidate of Philological Sciences, \\ Associate Professor of English Philology Department \\ Uzhhorod National University \\ Slyvka N. T. \\ Senior Teacher of Department of Foreign Languages \\ Uzhhorod National University \\ Uzhhorod, Ukraine
}

The quality of education is one of the important factors determining the success of a graduate of an educational institution. Despite some developments, in practice, when evaluating learning outcomes, needs, motivations and interests of the student are not always taken into account. Peer 